\section{Doctors and ageism}

Ageism, defined as "discrimination against the old on the grounds of their being old," emerged as a concept in the United States in the 1960s and promptly joined racism and sexism in the rogues' gallery of social attitudes unacceptable to pressure groups. The Grey Panthers, having found their demon, fought it with commendable zeal and effect. People, it seemed, could be made to feel uncomfortable if accused of even quite recently identified discriminatory attitudes or practices.

The idea of ageism is less familiar in Britain, but that should not make us complacent. Though to many an uncouth neologism, the word at least invites us to examine our prejudices, and the intended analogy with racism suggests an illuminating exercise. Would we dare translate our less amiable generalisations about elderly patients, our more exasperated reactions to them, directly into terms of colour? ("Don't you find it depressing working with black patients all the time?" "Twelve new admissions last night and only three of them white." "How can I be expected to run a teaching medical ward with all these beds blocked by, ahem, ethnic minorities?") The point need not be laboured. Perhaps some doctors are ageist, some of the time at least.

Such systematic research as has been carried out on the subject, mainly among medical students, confirms that a problem exists. ${ }^{23} \mathrm{~A}$ negative attitude to the elderly-"a medical prejudice against old patients" simply because so many patients are old and many clinical encounters will therefore be vitiated if doctors are reluctant, ambivalent, or hostile towards them. Older patients have too many diagnoses and insufficient respect for the traditional specialty boundaries of medicine. They may offer slow and elusive histories and may have, in most cases through no fault of their own, social problems. Their proper diagnosis and management may be less than straightforward for busy doctors in general practice and in the single organ specialties, where many contributing factors, ignorance of the basics of geriatric medicine perhaps included, may combine to produce frustration, exasperation, withdrawal, or rejection.

"We come to clinical medicine with humanity and after three years they have educated it out of us," observed a medical student quoted by Gale and Livesley in a 1971 study which showed that junior hospital doctors' attitudes to the care of the elderly were much less favourable than those of clinical medical students. ${ }^{4}$ Teaching hospital ageism, which can reasonably be held to account for the difference, is hard to resist but may not go on forever. The present generation of teachers is the last not widely exposed to undergraduate education in geriatric medicine, ${ }^{5}$ and recent evidence from the evaluation of such teaching efforts suggests that a better understanding of the special needs of elderly patients results in more positive attitudes towards their care. ${ }^{67}$

COLIN T CURRIE

Senior Lecturer in Geriatric Medicine,

City Hospital,

Edinburgh EH10 5SB

1 Green J. Newspeak: a dictionany of jargon. London: Routiedge and Kegan Paul, 1984.

2 Spence DL, Feigenbaum EM, Fitzgerald F, Roth J. Medical student attitudes toward the geriatric patient. F Am Geriatr Soc 1968;16:976-83.

3 Kutner NG. Medical students' orientation towards the chronically ill. $\mathcal{J}$ Med Educ 1978;53:111-8. 4 Gale J, Livesley B. Attitudes towards geriatrics: a report of the King's survey. Age Ageing 1974;3:49-53.

5 Smith RG, Williams BO. A survey of undergraduate teaching of geriatric medicine in the British medical schools. Age Ageing 1983;12(suppl):2-6.

6 Wattis JP, Smith CW, Binns V. Medical students' attitudes to old people and career preference: comparison of two universities. Med Educ 1986;20:498-501.

7 Linn BS, Zeppa R. Student attitudes about surgery in older patients before and after the surgical clerkship. Ann Surg 1987;205:324-8.

\title{
Time to stop putting the clocks back?
}

A strong case may be made on health grounds for keeping British Summer Time through the winter and stopping putting the clocks back one hour in the autumn. ${ }^{1}$ The main reason is that it would reduce road accidents, and the Royal Society for the Prevention of Accidents estimates from data produced by the Transport and Road Research Laboratory that keeping summer time would reduce fatal and serious accidents by 580 in Britain next year. ${ }^{23}$ The small increase in accidents in the darker mornings would be offset by a larger fall in the lighter late afternoons, and the reduction would be greatest among child pedestrians and cyclists. RoSPA claims that "it is difficult to identify any other single measure which would produce such a sizeable and immediate impact on road safety in Britain" and wants permanent summer time introduced as soon as possible.

The Policy Studies Institute has recently argued the general case for keeping British Summer Time, which includes a reduction in burglaries, savings in fuel costs, increased opportunities for outdoor leisure, an extension of the tourist season, and harmonisation of time zones in western Europe. ${ }^{1}$ The main arguments against are that outdoor workers would have to spend longer in the dark in the early mornings and that the sun would rise very late in the far north. Yet most organisations contacted by the Policy Studies Institute favour keeping summer time all year. The institute has even presented the case for double summer time, which would further reduce accidents and increase leisure time.

The health arguments for keeping summer time rest not only on reducing road traffic accidents but also on general improvements in physical and mental health. Many people are at their worst first thing in the morning and a later sunset could well raise their spirits during the shorter hours of daylight in winter. The young and old and their relatives would be less anxious about the possibility of assault as they would have longer daylight hours to complete their travelling, and the elderly might get out more and so keep up their vitamin D concentrations.

The benefits of keeping summer time would be somewhat less than those achieved by making it compulsory to wear seatbelts. Nevertheless, doctors should consider campaigning on keeping summer time as they campaigned on seat belts.

District Medical Officer,

J G AvERY

South Warwickshire Health Authority,

Warwick CV34 4DE

1 Hillman M. Putting the clock forward by one hour. London: Policy Studies Institute, 1987.

2 Transport and Road Research Laboratory. The potential accident benefits of reintroducing British standard time. TRRL leaflet LF1027. Crowthorne, Berks: TRRL, 1986.

3 Royal Society for the Prevention of Accidents. Let there be light! Care on the road. Birmingham: RoSPA, 1987. 